\title{
A Normatização do AEE na Educação Infantil Municipal de Niterói
}

The Standardization of the ESA in infantile education Municipal de Niterói

La estandarización de la ESA en la educación infantil Municipal de Niterói

\section{* Fernanda Viannay Siqueira dos Santos}

Professora mestre na Fundação Pública Municipal de Educação de Niterói, Niterói, Rio de Janeiro, Brasil. viannay25@hotmail.com - https://orcid.org/0000-0002-3925-0416

\section{** Paulo Pires de Queiroz}

Professor doutor na Universidade Federal Fluminense, Niterói, Rio de Janeiro, Brasil. ppqueiroz@yahoo.com.br - https://orcid.org/0000-0002-0609-6424

Recebido em 28 de maio de 2018

Aprovado em 16 de outubro de 2018

Publicado em 06 de maio de 2019

\section{RESUMO}

Este artigo apresenta parte de uma pesquisa de mestrado da Universidade Federal Fluminense, que teve como objetivo identificar o ciclo de políticas públicas da Educação Especial no munícipio de Niterói. Assim como analisar a maneira como tais políticas em favor das crianças com necessidades educacionais especiais, menores de seis anos, tem se materializado nesse sistema municipal de ensino. A apuração dos dados reunidos acerca do contexto histórico-social que compõe a fundamentação teórica desta investigação, adicionada às entrevistas realizadas com os professores e gestores que evidenciam o contexto da prática e mais as análises dos documentos oficiais que imprimem o contexto das normas, compuseram a triangulação de dados realizada à luz do "ciclo de políticas", proposto por Ball e Bower (1992). No estudo, o recurso empregado expôs por meio dos objetivos alcançados, o imperativo de praticar a política proposta (Oficial) como a política de fato e a necessidade de ressignificar a política em uso (práticas de campo) pelos profissionais responsáveis pela implementação da Lei ou da política, fortalecendo o ensino inclusivo na educação infantil da rede municipal de Niterói através do Atendimento Educacional Especializado.

Palavras-chave: Atendimento Educacional Especializado; Políticas Públicas; Educação Infantil.

\section{ABSTRACT}

This paper presents part of a master's degree from Universidade Federal Fluminense, which aimed to identify the public policy cycle of Special education in municipality of Niterói. As well as examining the way such policies in favor of children with special educational needs, 
children under six years old, has materialized in this municipal education system. The analysis of the data gathered about the historical-social context that makes up the theoretical foundation of this research, added to the interviews with teachers and administrators to show the context of the practice and analysis of official documents that print the standards context, composed the triangulation of data held in the light of the "policy cycle", proposed by Ball and Bower (1992). In the study, the employee resource exposed through the objectives achieved, the imperative to practice the proposed policy (official) as the de facto policy and the need to resign the policy in use (field practice) by professionals responsible for implementation of the law or politics, strengthening the inclusive teaching in early childhood education from the public Educational Service through Specialized Niterói.

Keywords: Educational Service; Public Policies; Early Childhood Education.

\section{RESUMEN}

Este artículo presenta parte de un Máster de la Universidade Federal Fluminense, que tuvo como objetivo identificar el ciclo de las políticas públicas de Educación Especial en Municipio de Niterói. Así como de examinar lo que necesita este tipo de políticas a favor de los niños con educación especial, niños menores de seis años, se ha materializado en este sistema de educación municipal. El análisis de los datos recogidos sobre el contexto histórico-social que constituye el fundamento teórico de esta investigación, añadido a las entrevistas con maestros y administradores para mostrar el contexto de la práctica y el análisis de documentos oficiales imprimir el contexto de normas, compuesto por la triangulación de datos, habida cuenta el "ciclo de la política", propuesto por bola y Bower (1992). En el estudio, el recurso empleado expuesto a través de los objetivos alcanzados, el imperativo para la práctica de la política propuesta (oficial) como la política de hecho y la necesidad de renunciar a la política de usan (práctica de campo) por profesionales responsables de aplicación de la ley o la política, fortalecer la enseñanza inclusiva en la educación preescolar desde el servicio público educativo a través de Niterói especializada.

Palabras clave: Servicio educativo; Políticas públicas; La educación temprana.

\section{O AEE na Educação Infantil: uma breve introdução}

A inclusão do atendimento à criança de zero a seis anos no sistema educacional do nosso país só aconteceu recentemente e por força da Lei. Na Constituição Federal de 1988, o status de cidadão, conferido ao indivíduo desde o seu nascimento, permitiu que, ao longo das décadas seguintes, outros ordenamentos legais fossem criados ou reformulados, de maneira a garantir a essa parcela da população a criação de políticas públicas importantes para a manutenção de ações específicas ao atendimento a essa etapa do desenvolvimento humano.

Nessa mesma conjuntura, o atendimento à pessoa com deficiência também recebe um tratamento peculiar na Constituição Federal de 1988, em seu artigo 228, inciso III, no 
http://dx.doi.org/10.5902/1984686X32798

qual encontramos a garantia de oferta do Atendimento Educacional Especializado aos portadores de deficiência, preferencialmente na rede regular de ensino.

Depois da Constituição de 1988, a Lei 7.853/89, que dispõe sobre o apoio às pessoas portadoras de deficiência, também assegurou, entre outras coisas, o amparo à infância mediante oferta da educação especial como modalidade educativa:

A inclusão, no sistema educacional, da Educação Especial como modalidade educativa que abranja a educação precoce, a pré-escolar, as de $1^{\circ}$ e $2^{\circ}$ graus, a supletiva, a habilitação e reabilitação profissionais, com currículos, etapas e exigências de diplomação própria. (BRASIL, 1989, p. 1)

Segundo Fernandes e Orrico (2013), a partir da década de 1990, algumas conferências internacionais geraram declarações e pactos para a inclusão de segmentos historicamente excluídos. Tivemos a Conferência de Educação para Todos, em 1990; a Declaração de Salamanca, em 1994; a Declaração para o 3ํmilênio, de 1999; a Declaração de Dakar, de 2000; a Declaração de Madri, de 2002; Declaração de Santa Cruz de La Sierra, de 2004, e a Convenção Internacional de Direitos da Pessoa com Deficiência, de 2006, que foi incorporada ao texto da Constituição Brasileira pelo Decreto 6949, de 2009.

Ainda na década de 1990, o Estatuto da Criança e do Adolescente, Lei nº 8.069/90 e a LBDEN 9394/96 reafirmam a Constituição com artigos específicos tanto para a educação infantil quanto para a educação especial. Entre eles, destacamos, no ECA, o Art. 3, Parágrafo Único (incluído pela Lei nำ13.257, de 2016):

Os direitos enunciados nesta Lei aplicam-se a todas as crianças e adolescentes, sem discriminação de nascimento, situação familiar, idade, sexo, raça, etnia ou cor, religião ou crença, deficiência, condição pessoal de desenvolvimento e aprendizagem, condição econômica, ambiente social, região e local de moradia ou outra condição que diferencie as pessoas, as famílias ou a comunidade em que vivem. (BRASIL, 2016, p. 1) - Grifo Nosso.

Em 1994, as orientações oriundas da Política Nacional de Educação Especial levaram o MEC a elaborar as diretrizes educacionais sobre estimulação precoce para os portadores de necessidade educacionais especiais, que, ancorada na proposta de integração, tinham como finalidade estabelecer as diretrizes para fundamentar os programas em pauta e a necessidade de determinar a natureza educacional desses programas em suas modalidades unifocal e multifocal.

Depois disso, o Referencial Curricular Nacional para a educação infantil, lançado em 1998, traz no corpo da introdução do volume um, um tópico dedicado à educação de crianças com necessidades educacionais especiais, no qual se ressalta que, segundo a LDB/96, a educação especial tem início na faixa etária de zero a seis anos, durante a 
educação infantil.

A partir daí, o Decreto 3.298/99 que regulamenta a Lei № 7.853/89, as Diretrizes Nacionais para a Educação Especial na Educação Básica (Resolução CNE/CEB no 2/2001), o Plano Nacional de Educação - PNE, Lei 10.172/2001, o Decreto oㅜ 6.094/07 e a Política Nacional de Educação Especial na Perspectiva da Educação Inclusiva, lançada em 2008, definem a educação especial como uma modalidade transversal a todos os níveis e modalidades de ensino; indicam o caráter complementar ou suplementar ${ }^{1}$ de escolarização do Atendimento Educacional Especializado, organizado no contraturno do processo de escolarização comum/regular, e, entre outras coisas, destacam a construção de uma escola inclusiva de qualidade, gratuita e em igualdade de condições para todos.

De acordo com Glat e Fernandez (2005):

\begin{abstract}
Neste contexto é que se descortina o novo campo de atuação da Educação Especial. Não visando importar métodos e técnicas especializados para a classe regular, mas sim, tornando-se um sistema de suporte permanente e efetivo para os alunos especiais incluídos, bem como para seus professores. Como mencionado, a Educação Especial não é mais concebida como um sistema educacional paralelo ou segregado, mas um conjunto de recursos que a escola regular deverá dispor para atender à diversidade de seus alunos. (GLAT e FERNANDEZ, 2005, p. 5).
\end{abstract}

Para dar conta dessa nova lógica, o Atendimento Educacional Especializado, organizado com aporte da educação especial e oferecido por meio da organização das Salas de Recursos Multifuncionais, torna-se uma modalidade de serviço exclusiva de nosso país. Foi instituído pelo Decreto 7.611 , em 17 de novembro de 2011, depois de tensões entre os partidários da política de inclusão total e os defensores da inclusão com manutenção dos suportes mais restritivos (classes especiais e escolas especiais). Esse serviço, oferecido mediante a dupla matrícula dos alunos público-alvo da educação especial, segundo o Art. 2º, parágrafo 20 do Decreto supracitado, deve:

\begin{abstract}
O atendimento educacional especializado deve integrar a proposta pedagógica da escola, envolver a participação da família para garantir pleno acesso e participação dos estudantes, atender às necessidades específicas das pessoas público-alvo da educação especial, e ser realizado em articulação com as demais políticas públicas. (BRASIL, 2011, p. 1)
\end{abstract}

Em 04 de agosto de 2015, o MEC em parceria com SECADI/DPEE-SEB/DICEI publicam a Nota Técnica Conjunta no 02 , com orientações para a organização e oferta do

1 Complementar à formação dos estudantes com deficiência, transtornos globais do desenvolvimento [...]. Suplementar à formação de estudantes com altas habilidades/superdotação. 
http://dx.doi.org/10.5902/1984686X32798

Atendimento Educacional Especializado na educação infantil. $O$ documento, que inicialmente discorre acerca do direito das crianças à educação, trata da institucionalização e a operacionalização do Atendimento Educacional Especializado nas creches e préescolas. Logo, além de destacar as atribuições do AEE, ressalta que o trabalho não deve se restringir à Sala de Recursos, mas se estender a toda a escola.

$O$ atendimento às crianças com deficiência é feito no contexto da instituição educacional, que requer a atuação do professor do AEE nos diferentes ambientes, tais como: berçário, solário, parquinho, sala de recreação, refeitório, entre outros, onde as atividades comuns a todas as crianças são adequadas às suas necessidades específicas. (BRASIL, 2015, p. 5)

Diante da trajetória de produção da política como texto (BALL e BOWE, 2011), em âmbito nacional, torna-se necessário desenvolver uma análise das políticas educacionais dirigidas a criança de zero a seis anos em âmbito municipal, uma vez que cabe a essa esfera a concretização das políticas na Educação Básica.

\section{O Atendimento Educacional Especializado na Rede Municipal de Niterói}

O Atendimento Educacional Especializado, apontado desde a Constituição de 1988 como direito das pessoas com deficiência, matriculadas nos diferentes sistemas e modalidades de ensino, configura-se atualmente como um serviço oferecido pela educação especial à escola regular e é apoio importante para a permanência qualitativa dos estudantes com necessidades educacionais especiais incluídos nos diferentes segmentos educativos do nosso país.

Apesar de atualmente fazer parte da política de inclusão elaborada pelo MEC, esse serviço esteve, por muitos anos, restrito a uma educação segregada, sendo oferecido aos alunos com base numa abordagem clínica ou compensatória que visava basicamente à normalização dos indivíduos que eram atendidos nesse espaço. Tal afirmação pode ser confirmada quando nos debruçamos sobre a história da educação especial no município de Niterói. Segundo Fontes (2007):

A história da Educação Especial no município de Niterói começou no ano de
1986, com a criação do Centro Municipal de Educação Especializada,
"considerado o primeiro no gênero na América Latina" (Pintor, 2004, p. 23).
Seu objetivo era oferecer suporte, através do atendimento clínico, aos 68
alunos com dificuldades de aprendizagem matriculados na Rede. Em 1988,
o centro passou a se chamar Núcleo Municipal de Apoio à Aprendizagem
(NUMA), sendo extinto em 1993. (FONTES, 2007, p. 93).

Esse modelo de atendimento, baseado na lógica da normatização e da integração, 
perdurou também, na rede municipal, até a criação da Coordenação de Educação Especial, no final da década de 90. A partir da criação desta Coordenação, a lógica de atendimento modificou-se consideravelmente. As demandas por direitos, advindos dos acordos internacionais, ordenamentos legais e por empenho de segmentos sociais e políticos, ressaltam a perspectiva da inclusão.

De acordo com as informações coletadas na entrevista que realizamos com a Professora Doutora Nelma Pintor ${ }^{2}$, contidas também em documentos internos disponibilizados pela Assessoria de Educação Especial da FME, o Atendimento Educacional Especializado, organizado por meio da Sala de Recursos, foi instituído pela Coordenação de Educação Especial, em uma escola regular do município de Niterói, pela primeira vez no ano de 2000, antes do Programa de Implantação de Salas de Recursos Multifuncionais, lançado pelo Governo Federal, em abril de 2007, com a Portaria Normativa nํ 13, conforme afirma professora doutora Nelma Pintor em entrevista a esta pesquisa:

Primeiro, na escola Sebastiana Gonçalves Pinto. A diretora era fabulosa! Depois veio a do Altivo César, no Barreto. As diretoras nos contavam como esse tipo de trabalho facilitava o trabalho pedagógico na sala de aula comum. O município foi dando condições e manteve com verba própria essas primeiras Salas de Recursos. (Entrevista com a Professora Doutora Nelma Pintor, realizada em 10.04. 2017).

Apesar do Atendimento Educacional Especializado, organizado por meio da Sala de Recursos, ter sido iniciado em 2000, a regulamentação do serviço, em âmbito municipal, só aconteceu em 2003, mediante a Portaria SME/FME 407. Esse fato demonstra a maneira como as políticas públicas de inclusão foram estruturadas no município. Com isso, nota-se que primeiro se executou a Lei e, depois, se organizou a política. Essa prática foi retratada na entrevista concedida pela Professora Doutora Nelma Pintor, na qual, em determinado momento, ela nos diz:

Se a LDB vinha com a ordenança de cima para baixo. Como fazer a inclusão? Como dar conta de uma educação que já havia caminhado mais de 500 anos pra trás e essas crianças, jovens e adultos continuam segregados? Então... Também usamos a seguinte concepção: É no caminhar que você aprende a caminhar. Você faz o seu caminho, caminhando. (Entrevista com a Professora Doutora Nelma Pintor, realizada em 10.04. 2017).

Com o êxito da proposta de criação da primeira Sala de Recursos do município, novas salas foram inauguradas nos anos seguintes. Em 2007, ano de lançamento do Programa Federal de Salas de Recursos Multifuncionais, Niterói já contava com trinta e uma salas.

2 Doutora em Ciências da Criança e da Mulher pelo Instituto Fernandes Figueira/FIOCRUZ (2012). Coordenou a Educação Especial da Secretaria Municipal de Educação de Niterói/RJ desde maio 1999 até junho de 2013. 
Nos anos seguintes, a demanda de matrícula aumentou e novas Salas de Recursos foram organizadas dentro das unidades escolares com a ajuda do programa do MEC.

Conforme informação do relatório final da Assessoria de Educação Especial do município em questão, referente ao ano de 2016, a rede conta atualmente com sessenta e três Salas de Recursos. No tópico que trata do Atendimento Educacional Especializado, o documento informa que o município conta atualmente com sessenta e três Salas de Recursos Multifuncionais, oitenta professores de AEE atendendo a aproximadamente mil e cinquenta alunos com necessidades educacionais especiais.

O relatório disponibilizado pela Assessoria de Educação Especial não traz informações detalhadas sobre a especificidade do atendimento nos diferentes segmentos. Os segmentos são identificados apenas pelo nome das escolas encontradas nos quadros com quantitativos de alunos e professores de apoio, organizados por polos. Somente a Educação de Jovens e Adultos aparece em um quadro separado. Por isso, somente após analisar e tratar as informações contidas nos quadros, foi possível construir a ilustração a seguir:

Gráfico 1- Salas de Recursos por segmento na Rede Municipal de Niterói

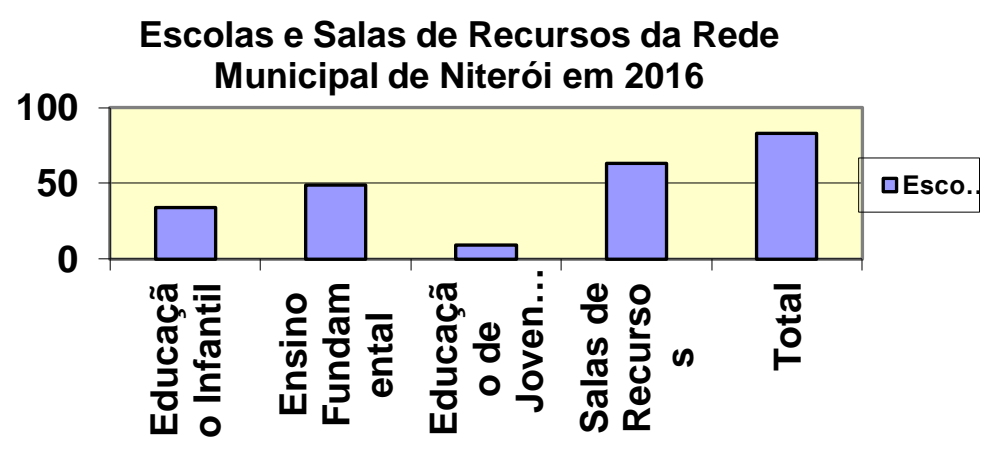

Fonte: Elaborado a partir dos dados fornecidos pelo Relatório anual da Ass. De ed. Esp. da FME/Niterói.

Observando as informações do gráfico 1, nota-se que o quantitativo de Salas de Recursos é bem próximo do total de escolas da rede municipal. No entanto, o relatório não especifica a quantidade de Salas de Recursos em cada segmento, uma vez que há, nessa rede de ensino, escolas municipais que atendem aos três segmentos. Assim, no caso das escolas municipais, pode haver unidades atendendo ao ensino fundamental, à educação infantil e à EJA.

Apesar da dificuldade de descrever a quantidade de Salas de Recursos em cada segmento escolar municipal de Niterói, observa-se que todo o crescimento, relativo à oferta 
do Atendimento Educacional Especializado, percebido até o ano de 2016, só foi possível, porque no ano de 2004, Niterói avançou na política de implantação da perspectiva inclusiva com a ajuda do Programa Educação Inclusiva: direito à diversidade.

Figura 1- Reportagem da Revista Gestão Universitária- Agosto de 2004

Noticias $14 / 08 / 2004$

If Curtir $0 \longdiv { G + 1 } 0$

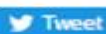

\section{Programa Educação Inclusiva é implantado em Niterói}

O município de Niterói, no Estado do Rio de Janeiro, é o mais novo parceiro do Programa Educaçāo Inclusiva: Direito à Diversidade, da Secretaria de Educaçāo Especial (Seesp/MEC).

Nesta semana, o programa foi implantado na cidade por meio da Secretaria Municipal de Educação (SME) e da Fundação Municipal de Educação (FME), com o objetivo de garantir o acesso e a permanência de todas as crianças, jovens e adultos com necessidades educacionais especiais no sistema regular de ensino.

Segundo a secretária municpal de Educaçāo de Niterói e presidente da Fundação Municipal de Educação, a professora Maria Felisberta Trindade, a prefeitura irá subsidiar filosốfica e tecnicamente o processo de transformaçāo do sistema educacional municipal. "Queremos envolver as comunidades, em especial a escolar, para compreender a educaçāo inclusiva como um direito humano fundamental e base para uma sociedade mais justa e solidária".

Atualmente a cidade possui cerca de 31 mil estudantes na rede de ensino - infantil, fundamental, educaçāo de jovens e adultos e creches. Destes, aproximadamente quinhentos sảo portadores de alguma deficiência física.

As informaçōes sāo da Assessoria de Comunicaçāo do Ministếrio da Educaçāo.

0 comentários

Classificar por Mais antigos -

Fonte: http://gestaouniversitaria.com.br/artigos/programa-educacao-inclusiva-e-implantado-em-niteroi Acesso: 01.07.2017

O programa, criado pelo MEC em 2003, para apoiar a formação de gestores e educadores, a fim de transformar os sistemas educacionais em sistemas inclusivos, contribuiu com apoio técnico e financeiro por meio da organização dos municípios em polos para a formação regional. Atento às exigências do programa, Niterói apresentou sua demanda e participou ativamente das formações como um dos municípios-polo.

Em 2007, depois de um processo coletivo iniciado em abril de 2005, por determinação do então secretário de educação e depois de reivindicações da própria rede, chega às Unidades de Ensino a primeira versão do texto final da Proposta Pedagógica da Secretaria e da Fundação Municipal de Educação de Niterói. O sistema de ensino do município, organizado agora em Ciclos, trata da Educação Inclusiva como parte do conhecimento e 
http://dx.doi.org/10.5902/1984686X32798

valorização da diversidade. Concebendo-a como fator de enriquecimento do processo educacional, propõe a necessidade de desfazer a cultura da segregação e de mudar a ideia de que a deficiência está associada à incapacidade, preconiza a necessidade de desenvolvimento de novas metodologias, estratégias, ajustes, modificações e adaptações curriculares para atender às necessidades educacionais especiais.

Na Portaria FME 878/2009, a Educação Especial, entendida na perspectiva da Inclusão, foi organizada com vista a atender aos alunos que apresentam necessidades educacionais especiais (NEE) em caráter permanente ou temporário, deficiência física, sensorial ou mental, síndromes, altas habilidades/ superdotação e transtornos globais do desenvolvimento.

Para atender aos alunos com necessidades educacionais especiais, incluídos na Rede, a legislação municipal garante, por meio da Assessoria de Educação Especial da FME, suporte pedagógico especializado às unidades de ensino, contando com a atuação de um agente de inclusão, com o trabalho na Sala de Recursos com professor especializado na própria unidade e com o acompanhamento de um professor de apoio em suas atividades cotidianas, mediante parecer da Coordenação de Educação Inclusiva da FME.

A inovação do atendimento aos alunos com necessidades educacionais especiais trouxe um desafio para a política educacional do município, a adoção de sistemas de bidocência/ ensino colaborativo (BEYER, 2005), ou seja, professores especialistas atuando em colaboração com os professores de classe. Tais sistemas configuraram, no município de Niterói, uma estratégia para a efetivação de uma educação, de fato, inclusiva.

Todo o percurso histórico delineado nesta seção constata que, o período de efervescência da política de implantação do programa de Salas de Recursos no município, foi delineado a partir de um contexto de produção de texto advindo da instância federal, ou seja, à medida que novas leis e programas foram criados pelo governo federal e pelos movimentos internacionais, Niterói se organizou para dar conta dos direitos que se consolidavam em meio ao embate entre as perspectivas dos grupos participantes da produção do texto acerca da educação básica, da inclusão e da necessidade do AEE.

\section{O Percurso da Educação Infantil Municipal de Niterói na Perspectiva da}

\section{Inclusão}

A história da educação infantil em Niterói percorre caminhos sinuosos e contraditórios. A diversidade de atendimento oferecido às crianças de zero a seis anos, no referido 
http://dx.doi.org/10.5902/1984686X32798

município, é marcada por instituições de diferentes categorias administrativas que, conforme a LDB, compõem o seu sistema de ensino. A saber:

Art. 19. As instituições de ensino dos diferentes níveis classificam-se nas seguintes categorias administrativas:

I - públicas, assim entendidas as criadas ou incorporadas, mantidas e administradas pelo poder público;

II - privadas, assim entendidas as mantidas e administradas por pessoas físicas ou jurídicas de direito privado.

Art. 20. As instituições privadas de ensino se enquadrarão nas seguintes categorias:

I - particulares em sentido estrito, assim entendidas as que são instituídas e mantidas por uma ou mais pessoas físicas ou jurídicas de direito privado que não apresentem as características dos incisos abaixo;

II - comunitárias assim entendidas as que são instituídas por grupos de pessoas físicas ou por uma ou mais pessoas jurídicas, inclusive cooperativas educacionais, sem fins lucrativos, que incluam na sua entidade mantenedora representantes da comunidade; (Redação dada pela Lei ํㅜ 12.020, de 2009) III - confessionais assim entendidas as que são instituídas por grupos de pessoas físicas ou por uma ou mais pessoas jurídicas que atendem à orientação confessional e ideologia específicas e ao disposto no inciso anterior;

IV - filantrópicas, na forma da lei. (BRASIL, 1996, p. 12)

Somente em 1978 que Niterói começa a reunir esforços significativos para atender às crianças da primeira infância. No entanto, essas ações atreladas à Coordenadoria de Promoção Social e à Coordenadoria de Bem-estar Social mantinham concepções de cunho preventivo, assistencial e compensatório.

Após 1990, com a promulgação da Lei Orgânica Municipal e com a política de inclusão se estruturando, o atendimento à criança de zero a seis anos começa a conquistar espaço e importância no sistema educacional do município. A partir do Decreto 6035/91, algumas das creches existentes no município passaram a fazer parte da FME, galgando, assim, segundo Picanço (2003), a visão de "espaço educativo e democrático".

(...) o atendimento educacional das crianças de 0 a 4 anos, em creches, e de 4 a 6 anos em pré-escolas, com o objetivo de promover o desenvolvimento físico, emocional e intelectual das crianças dessa faixa etárias. (NITERÓI, 1990, p. 55)

Além disso, com a promulgação da LBDEN/96 e a criação do RCNEI, a necessidade de reflexão sobre a prática docente neste segmento impeliu o município a repensar a disposição da mão de obra na educação infantil, privilegiando, então, a permanência de quadros docentes, extinguindo gradativamente os quadros de auxiliares de creche e ofertando formação pedagógica aos profissionais ainda em exercício.

Para dar conta dessas e de outras questões, em 1999, como resultado do "movimento de discussões com profissionais da rede", foi lançada a proposta pedagógica "Construindo a Escola do Nosso Tempo", que apontava para a organização do sistema em Ciclos. Apesar 
http://dx.doi.org/10.5902/1984686X32798

de encontrarmos, nesse documento, um específico para a educação infantil, a ausência de uma discussão consistente sobre o atendimento aos alunos nas creches e pré-escolas pouco contribuiu para delinear a política de atendimento municipal.

Somente em 2000, com a publicação da Portaria FME nํ. 134/00, o atendimento à criança de zero a cinco anos passou a ser oferecido em Unidades Municipais de Educação Infantil (UMEI). A creche, que, nesse período, passou a fazer parte do Projeto de Educação Infantil Municipal, compôs com a pré-escola o Ciclo Infantil.

Em 2007, chega às Unidades de Ensino a primeira versão do texto final da Proposta Pedagógica da Secretaria e da Fundação Municipal de Educação de Niterói. O documento, que repensa o sistema de ensino do município, organizado em Ciclos, apresentou-se com o objetivo de flexibilizar o tempo de aprendizagem, superando a lógica tradicional de organização seriada.

Assim como acontece no ensino fundamental, em seu anexo, a Proposta aponta que o atendimento aos alunos do Ciclo Infantil nas Unidades aconteça a partir de agrupamentos de alunos, nos chamados Grupos de Referência. O processo inicial de organização dos alunos nos grupos é baseado no critério etário, respeitando-se o quantitativo máximo de alunos por grupo, em função da idade, da inclusão de alunos com necessidades educacionais especiais e do espaço.

Quando há aluno com necessidade educacional especial incluído, o quantitativo de crianças por grupo de referência deve ser modificado. Admitem-se, depois das necessidades apontadas e após avaliação da Equipe de Educação Especial da FME, atendimentos na Sala de Recursos e professor de apoio para os casos mais complexos. Esse quantitativo, atualmente, está descrito na Portaria 87/2011 da seguinte maneira:

\begin{abstract}
Art. 10: A inclusão de alunos com necessidades educacionais especiais (NEE) em cada Grupo de Referência obedecerá à seguinte composição: I na Educação Infantil: a) Grupos de Referência com alunos de 4 meses a 11 meses serão compostos por 6 alunos e 2 com NEE, totalizando 8 alunos; b) Grupos de Referência com alunos de 1 ano até 1 ano e 11 meses serão compostos por 6 alunos e 2 com NEE, totalizando 8 alunos; c) Grupos de Referência com alunos de 2 anos até 2 anos e 11 meses serão compostos por 10 alunos e 2 com NEE, totalizando 12 alunos; d) Grupos de Referência com alunos de 3 anos até 3 anos e 11 meses serão compostos por 15 alunos e 2 com NEE, totalizando 17 alunos; e) Grupos de Referência com alunos de 4 anos a 4 anos e 11 meses serão compostos por 15 alunos e 2 com NEE, totalizando 17 alunos; f) Grupos de Referência com alunos de 5 anos a 5 anos e 11 meses serão compostos por 15 alunos e 2 com NEE, totalizando 17 alunos. (NITERÓI, 2011, p. 3)
\end{abstract}

Em 2011, a Portaria da FME 87, que foi alterada em 2014, organiza o segmento da 
http://dx.doi.org/10.5902/1984686X32798

educação infantil por critério etário, apresenta a educação especial na perspectiva inclusiva, detalha os direitos dos alunos com necessidades educacionais especiais, especifica as funções do AEE e as funções do professor de apoio.

Outro importante movimento em direção à ampliação da educação infantil na perspectiva inclusiva em Niterói foi o lançamento, no ano de 2013, do programa Mais Infância. A iniciativa municipal viabilizada pelo programa Brasil Carinhoso, lançado pelo FNDE/MEC em 2012, que objetiva transferir automaticamente recursos financeiros para os municípios custearem despesas com manutenção e desenvolvimento da educação infantil, contribuiu com a ampliação do acesso e a permanência da criança com e sem deficiência na educação infantil, conforme mostra o quadro apresentado no III CONEDU pela Superintendência de Ensino da Fundação Municipal de Educação de Niterói, anexado a seguir:

Quadro 1- Evolução da Educação Infantil na Rede Municipal de Niterói

\begin{tabular}{|c|c|c|c|c|c|c|c|c|c|}
\hline \multicolumn{10}{|c|}{ Educação Infantil } \\
\hline \multicolumn{5}{|c|}{ Unidades de Atendimento na Educação Infantil } & \multicolumn{5}{|c|}{ Quantitativo de Alunos na educação Infantil } \\
\hline & $\begin{array}{l}2012 \text { - } \\
\text { Nov. }\end{array}$ & $\begin{array}{l}2016 \text { - } \\
\text { Junho }\end{array}$ & $\begin{array}{l}\text { Crescimento } \\
\text { Quantitativo }\end{array}$ & $\begin{array}{c}\% \text { de } \\
\text { Crescimento }\end{array}$ & & $\begin{array}{l}2012 \text { - } \\
\text { Nov. }\end{array}$ & $\begin{array}{l}2016 \text { - } \\
\text { Junho }\end{array}$ & $\begin{array}{l}\text { Crescimento } \\
\text { Quantitativo }\end{array}$ & $\begin{array}{c}\% \text { de } \\
\text { Crescimento }\end{array}$ \\
\hline $\begin{array}{l}\text { UMEI/ } \\
\text { NAEI }\end{array}$ & 26 & 42 & 16 & $61,54 \%$ & $\begin{array}{l}\text { UMEI/ } \\
\text { NAEI }\end{array}$ & 5.067 & 6.415 & 1.348 & $26,60 \%$ \\
\hline
\end{tabular}

Fonte:https://editorarealize.com.br/revistas/conedu/trabalhos/TRABALHO_EV056_MD1_SA17_ ID11661_19082016172813.pdf Acesso em 01/11/2017

Embora reconheçamos os avanços significativos de tais iniciativas em direção a uma política efetiva de garantia do direito de matrícula das crianças de zero a cinco anos, na rede regular de ensino, observam-se no cotidiano das Unidades Municipais de Educação Infantil grandes dificuldades na manutenção de serviços importantes para a inclusão da criança com necessidades educacionais especiais.

\section{Considerações Finais}

Ao analisar o contexto da produção de textos normativos que versam sobre o Atendimento Educacional Especializado e a educação infantil em âmbito nacional percebemos que a organização do Atendimento Educacional Especializado e a inclusão da creche e da pré-escola no sistema educacional brasileiro se deram à luz dos movimentos de redemocratização do ensino a partir do direito e da inclusão dos alunos com ou sem necessidades educacionais especiais. 
A trajetória histórica de organização do Atendimento Educacional Especializado, considerando os contextos de influência e produção de textos em âmbito municipal, deixa evidente que o movimento de inclusão em Niterói originou-se do contexto de produção de texto advindo da instância federal, ou seja, à medida que novas leis e programas foram criados pelo governo federal e pelos movimentos internacionais, Niterói se organizou para dar conta dos direitos que se consolidavam em meio ao embate entre as perspectivas dos grupos participantes da produção do texto acerca da educação básica, da inclusão e da necessidade do AEE.

Considerando o histórico de organização do sistema municipal de ensino de Niterói, a inclusão da criança público-alvo da educação especial na educação infantil e especificando as concepções pedagógicas delineadas pelo sistema percebemos a maneira como as políticas públicas em favor das menores de seis anos, têm se materializado no sistema municipal de ensino de Niterói, quando ressaltamos o contexto de produção de texto.

Diante do exposto, percebemos que os resultados dessa investigação indicam que a disponibilização de serviços da educação especial para a inclusão da criança com necessidades educacionais especiais na educação infantil pressupõe a organização de políticas públicas diferenciadas que contemple a especificidade do primeiro segmento da educação básica.

\section{Referências}

BALL, Stephen J.; MAINARDES, Jefferson. Políticas educacionais: questões e dilemas. CORTEZ, 2011.

BALL, Stephen J.; BOWE, Richard. Subject departments and the 'implementation'of National Curriculum policy: an overview of the issues. Journal of Curriculum Studies, v. 24, n. 2, p. 97-115, 1992.

BEYER, Hugo Otto. Inclusão e avaliação na escola: de alunos com necessidades educacionais especiais. Mediação, 2013.

BRASIL. Decreto no 7.611, de 17 de novembro de 2011. Dispõe sobre a educação especial, o atendimento educacional especializado e dá outras providências. Diário Oficial da União, 2011.

BRASIL. Lei de Diretrizes e Bases da Educação Nacional (LDB). Lei Federal n. 9.394, de 26/12/1996.

BRASIL. Nota Técnica Conjunta n02/2015/MEC/SECADI/DPEE - SEB/DICEI. 
FERNANDES, Edicléa Mascarenhas; ORRICO, Hélio Ferreira. Documento Referência da CONAE 2014: Avanço, Retrocesso ou Negação da Educação Especial? Disponível em:http://www.uel.br/eventos/congressomultidisciplinar/pages/arquivos/anais/2013/AT022013/AT02-040.pdf. Acesso em: 15 jan. 2017

FONTES, Rejane de Souza. A educação inclusiva no município de Niterói (RJ): das propostas oficiais às experiências em sala de aula-o desafio da bidocência. 2007. $210 \mathrm{f}$. 2007. Tese de Doutorado. Tese (Doutorado em Educação) -Universidade do Estado do Rio de Janeiro, RJ.

GLAT, Rosana; FERNANDES, Edicléa Mascarenhas. Da educação segregada à educação inclusiva: uma breve reflexão sobre os paradigmas educacionais no contexto da educação especial brasileira. Revista Inclusão, v. 1, n. 1, p. 35-39, 2005.

NITERÓI. Lei Orgânica do Município de Niterói. Rio de Janeiro: Câmara Municipal de Niterói. 1990.

NITEROI. Portaria FME № 239, de 28 de setembro de 2001.

PICANÇO, Mônica Bezerra de Menezes. Desafios para a construção de um Plano Municipal de Educação. In: NITERÓI. Educação Infantil: subsídios para o Plano Municipal de Educação de Niterói. Niterói: FME, 2003.

\section{Correspondência}

Fernanda Viannay Siqueira dos Santos - Fundação Pública Municipal de Educação de Niteroi. Rua Visconde do Uruguai, 414. CEP: 24030075. Niterói, Rio de Janeiro, Brasil.

This work is licensed under a Creative Commons Attribution-NonCommercial 4.0 International (CC BY-NC 4.0) 